\title{
Vigilance in a Cooperatively Breeding Primate
}

\author{
Mojca Stojan-Dolar • Eckhard W. Heymann
}

Received: 25 March 2009 /Revised: 30 July 2009 / Accepted: 1 August 2009 /

Published online: 2 February 2010

(C) The Author(s) 2010. This article is published with open access at Springerlink.com

\begin{abstract}
Collective vigilance is considered a major advantage of group living in animals. We investigated vigilance behavior in wild mustached tamarins (Saguinus mystax), small, arboreal, cooperatively breeding New World primates that form stable mixed-species groups with saddleback tamarins (Saguinus fuscicollis). We aimed 1) to investigate whether vigilance patterns change according to individual activity and 2) to examine whether there is a social component of vigilance in their cooperative and nonaggressive society. We studied 11 factors that may influence vigilance and used this data to interpret the possible functions of vigilance. We observed 44 individuals in 3 mixed-species and 2 single-species groups of 2 populations that differed in population density and home range sizes. Vigilance changed greatly when individuals were engaged in different activities and individual vigilance was affected by different sets of factors depending on the activity. As vigilance decreased in proximity of conspecifics and heterospecifics when feeding, and in larger mixed-species groups when resting, we conclude that the predominant function of vigilance in mustached tamarins is predator related. However, the absence of the group size effect in very large single-species groups suggests that it may also function to maintain group cohesion. In the population with higher density and smaller home ranges individuals also increased their vigilance in home range overlap areas. We found no evidence that mustached tamarins monitor group mates to avoid food stealing or aggression. The effect of heterospecifics on individual vigilance suggests that collective vigilance might have been an important incentive in the evolution of tamarin mixed-species groups.
\end{abstract}

Keywords group living $\cdot$ mixed-species groups $\cdot$ predation $\cdot$ Saguinus mystax $\cdot$ social vigilance $\cdot$ vigilance

M. Stojan-Dolar $(\bowtie) \cdot$ E. W. Heymann

Department of Behavioral Ecology and Sociobiology, German Primate Center (DPZ), 37077

Göttingen, Germany

e-mail: mojca.stojan@arnes.si

M. Stojan-Dolar

Department of Sociobiology/Anthropology, Georg-August-University of Göttingen, Kellnerweg 6, 37077 Göttingen, Germany 


\section{Introduction}

Predation risk is considered one of the major evolutionary forces that led to group living in animals. Group living may yield antipredator benefits in terms of increased probability of predator detection due to collective vigilance (detection effect, Pulliam, 1973) and reduced individual risk of being attacked (dilution effect, Hamilton, 1971). As a consequence, researchers have observed a decrease in individual vigilance with increasing group size in many animal taxa (group size effect; Caro 2005), which implies increased safety in larger groups. However, there is an increasing number of examples, especially among primates, where this is not the case (Blumstein et al. 2001; Di Blanco and Hirsch 2006; Treves 2000). It has been suggested that distance to nearest neighbor or neighbor density is a better predictor of individual vigilance than total group size (Blumstein 1996; Pöysä 1994; Treves 2000). Depending on the species under study and their predators, vigilance can also be affected by other factors, such as habitat characteristics, sex, age, rank, presence of infants, and the individual's position in the group, which can confound with the group size effect (Caro 2005; Elgar 1989).

Vigilance is costly because it requires both time and visual attention and therefore it is at least partially incompatible with other activities (Bachman 1993; Childress and Lung 2003; Isbell and Young 1993). Most researchers report that animals are less vigilant during feeding than during resting (Cowlishaw 1998; Hirsch 2002; Kutsukake 2006). In primates in particular, vigilance is even further reduced during allogrooming (Chalmeau et al. 1998; Cords 1995; Hirsch 2002). Among the factors that influence vigilance behavior, individual activity often has the strongest impact on vigilance levels (Cords 1995; Hirsch 2002; Kutsukake 2006). Nevertheless, these studies did not investigate further how vigilance patterns change in different behavioral contexts even though the species under study show diverse activity patterns ( $c f$. Blumstein 1996; Bshary and Noë 1997; Chalmeau et al. 1998).

Independent of predation risk, vigilance in gregarious animals can also have social functions related to mating, avoiding aggression, scrounging, or maintaining contact with the group (Caro 2005). Social vigilance can be shaped by the type of social structure. Species with stronger hierarchies and higher levels of aggression, e.g., squirrel monkeys, are expected to show more social vigilance than more egalitarian species, e.g., red-bellied tamarins (Caine and Marra 1988). If animals are vigilant for social reasons, they would be expected to direct their scanning at other group members rather than at the environment. In the field, it is difficult to ascribe a function directly to a vigilance bout as it is hard to determine whether an individual is monitoring the environment or conspecifics. Moreover, it is also plausible to assume that these functions are combined, i.e., an individual could monitor the surroundings to check for predators and for group mates simultaneously. Consequently, studies of functions of vigilance depend largely on indirect assumptions derived from examining ecological and social factors that affect vigilance behavior (Caine 1984; Cowlishaw 1998; Hirsch 2002; Lima et al. 1999; Rose \& Fedigan 1995; Smith et al. 2004; Steenbeek et al. 1999).

Mustached tamarins (Saguinus mystax) provide an interesting model for a study on vigilance. Owing to their small body size, these arboreal New World monkeys are 
a subject to strong predation pressure, mostly by large raptors, but also by snakes and terrestrial predators such as ocelot and tayra (Heymann 1990a; Oversluijs Vasquez \& Heymann 2001; Peres 1993; Shahuano Tello et al. 2002). They have a highly cooperative social system with low levels of agonistic intragroup interactions and lack an apparent dominance hierarchy (Heymann 1990b; Heymann 1996). Only 1 female in the group breeds and all group members participate in rearing the offspring, usually twins (Garber 1997; Huck et al. 2004a). Mustached tamarins form stable mixed-species groups with saddleback tamarins (Saguinus fuscicollis), and the 2 species show vertical stratification in the forest where mustached tamarins live higher than saddlebacks. Shared vigilance is proposed to be one of the major reasons for the formation of these groups (Heymann \& Buchanan-Smith 2000).

We examined 1) whether vigilance patterns in mustached tamarins change according to individual activity and 2) whether there is a social component of vigilance in their cooperative and relatively nonaggressive society. To answer these questions we studied the factors that influence vigilance in different behavioral contexts to interpret the possible functions of vigilance. We predicted that 1) mustached tamarins would be more vigilant during resting than during feeding and least vigilant during allogrooming (Chalmeau et al. 1998; Cords 1995; Hirsch 2002). If vigilance has a predominantly antipredator function (Smith et al. 2004), we predicted that animals will relax their vigilance when they are 2) in the proximity of more close neighbors, 3) in the presence of conspecifics, 4) in the presence of heterospecifics, 5) when in larger single-species groups, and 6) when in larger mixed-species groups. Conversely, if vigilance increases with group size and neighbor density, it would indicate a major function of vigilance in social monitoring.

Based on other studies (Caro 2005; Goldizen 1989; Price et al. 1991; Savage et al. 1996) we predicted 7) that male mustached tamarins are more vigilant than females. We also predicted 8) adults to be more vigilant than juveniles (de A. Moura and Alonso 2000; Peres 1993; Savage et al. 1996). In most mammals, females with infants are more vigilant than females without young (Caro, 2005). Because in tamarins all group members help to carry and feed infants, we predicted 9) all group members to increase their vigilance while carrying infants. Because many raptors are ambush predators that gain most attack velocity in lower strata of the forest (Rettig 1978; Robinson 1994), vigilance is predicted to 10) decrease with height. Following the same line of thought, we also predicted 11) an increase in vigilance in areas where there is no immediate vegetation cover to prevent tamarins from being detected by raptors.

Vigilance in home range overlap areas can be related to mate defense or resource defense (Garber 1988; Isbell and Young 1993; Steenbeek et al. 1999; Terborgh 1983). The mate defense hypothesis would affect only male vigilance, while the resource defense hypothesis would concern both sexes equally. We have observed males in our focal populations aggressively preventing contact between females and neighboring males (Heymann 1996), and though rare, extragroup copulations have been reported (Huck et al. 2005). Our final prediction therefore was that 12) males, but possibly also females, will increase their vigilance in overlap areas. 


\section{Methods}

\section{Study Sites and Subjects}

Stojan-Dolar observed wild mustached tamarins at 2 sites in northeastern Peruvian Amazonia. The first site, Estación Biológica Quebrada Blanco (EBQB), is located ca. $70 \mathrm{~km}$ southeast of Iquitos $\left(4^{\circ} 21^{\prime} \mathrm{S}, 73^{\circ} 09^{\prime} \mathrm{W}\right)$ and is covered by primary tierra firme forest (Löttker et al. 2004). Stojan-Dolar observed 3 well habituated groups of mustached tamarins for 136 d between February 2006 and March 2007, covering both rainy and dry season. During the rainy season Stojan-Dolar observed each group for 5-6 d every month and during the dry season for 5-6 d every second month. The weighted mean group size \pm SE (relative to the proportion of time each group size and composition was observed) was $6.6 \pm 0.2$ (range: 5-9), including $2.9 \pm 0.2$ adult males (range: $2-5$ ) and $1.6 \pm 0.1$ adult females (range: $1-2$ ). They formed stable mixed-species groups (MSG) with $5.1 \pm 0.3$ saddleback tamarins (range: 2-8).

The second site, Padre Isla (PI), is a $c a .8 \mathrm{~km}^{2}$ island on the Amazon River near Iquitos $\left(3^{\circ} 44^{\prime} \mathrm{S}, 73^{\circ} 14^{\prime} \mathrm{W}\right)$. No primates originally lived on the island, but in 1977 , 1978 and 1980, Peruvian Primatological Project released wild-trapped mustached tamarins (Ique 2000). The island is covered by seasonally (January-May) flooded secondary forest and fruit and yucca plantations. Observations were possible during only the dry season. After a 2-mo habituation period, Stojan-Dolar observed 2 groups of mustached tamarins for 63 d between August 2006 and January 2007. She observed each group for $c a$. $10 \mathrm{~d}$ every second month. The mean group size ( $\pm \mathrm{SE}$ ) was $10.8 \pm 0.7$ (range: $8-14$ ), including $2.4 \pm 0.5$ adult males (range: $1-5$ ) and $2.8 \pm$ 0.1 adult females (range: 2-3). Because no other primates are present, mustached tamarins on PI live in single-species groups (SSG). We individually identified individuals at both sites by differences in pelage patterns, body size and shape, and pigmentation of reproductive organs (Löttker et al. 2004).

Predation pressure at different sites could differ, which would influence vigilance and render the analysis difficult. Because it is not possible to measure the predation pressure directly, Stojan-Dolar recorded alarm calls emitted by tamarins as a measure of perceived predation risk (Hill and Dunbar 1998). The rate of alarm calls was almost the same for both sites $(0.32$ per $10 \mathrm{~h}$ of observation per individual for EBQB and 0.31 for PI), so we were able to continue the analysis without controlling for predation pressure. However, the sites differ in some other potentially important aspects (Table I) so we nevertheless tested for differences between them and conducted separate analyses for EBQB and PI where needed.

\section{Observation Methods}

We defined vigilance as observable head movements in stationary individuals where scanning is directed beyond arm's reach (Treves 1998). We did not consider looking at own body, body of a grooming partner, objects close to own body, or objects held in hands as vigilance. We excluded looking beyond arm's reach in 2 cases because it is reasonable to assume that in these situations individuals cannot effectively perceive the environment: 1) staring without head movements in an unusual head 
Table I Comparison of the 2 study sites

\begin{tabular}{|c|c|c|c|c|c|c|}
\hline & EBQB1 & EBQB2 & EBQB3 & PI1 & PI2 & Comparison \\
\hline Home range area (ha) & 24 & 43 & 26 & 9 & 12 & $\mathrm{EBQB}>\mathrm{PI}$ \\
\hline$\%$ of overlap area & 32 & 28 & 36 & 25 & 20 & $\mathrm{EBQB}>\mathrm{PI}$ \\
\hline Saguinus mystax density per $\mathrm{km}^{2}$ & $20-26$ & $9-10$ & $13-18$ & $63-79$ & $72-92$ & $\mathrm{PI}>\mathrm{EBQB}$ \\
\hline $\begin{array}{l}\text { Saguinus sp. (mystax }+ \text { fuscicollis }) \\
\text { density per } \mathrm{km}^{2}\end{array}$ & $34-40$ & $19-24$ & $20-25$ & $63-79$ & $72-92$ & $\mathrm{PI}>\mathrm{EBQB}$ \\
\hline Feeding tree density per $\mathrm{km}^{2}$ & 223 & 87 & 138 & 198 & 255 & $\mathrm{PI} \geq \mathrm{EBQB}$ \\
\hline No. of feeding trees per home range & 78 & 51 & 55 & 25 & 39 & $\mathrm{EBQB}>\mathrm{PI}$ \\
\hline$\%$ of feeding trees in overlap area & 37 & 49 & 36 & 36 & 18 & $\mathrm{EBQB} \geq \mathrm{PI}$ \\
\hline $\begin{array}{l}\text { Intergroup encounters per } 100 \mathrm{~h} \text { of } \\
\text { observation }\end{array}$ & 6.8 & 4.1 & 3.3 & 7.9 & 7.4 & $\mathrm{PI}>\mathrm{EBQB}$ \\
\hline Adult/nonadult ratio & $1.33-2$ & $1-5$ & $1.33-2.5$ & $0.66-1$ & $0.86-1.6$ & $\mathrm{EBQB}>\mathrm{PI}$ \\
\hline Male/female ratio & $2-5$ & $1-3$ & $1-1.5$ & $0.67-1$ & $1-1.67$ & $\mathrm{EBQB} \geq \mathrm{PI}$ \\
\hline Diet & \multicolumn{3}{|c|}{$12-16 \%$ animal prey ${ }^{\mathrm{a}}$} & \multicolumn{2}{|c|}{$<5 \%$ animal prey ${ }^{\mathrm{b}}$} & \\
\hline Species composition & \multicolumn{3}{|c|}{ MSG } & \multicolumn{2}{|c|}{ SSG } & \\
\hline Habitat & \multicolumn{3}{|c|}{ Denser, higher } & \multicolumn{2}{|c|}{ More open, lower } & \\
\hline $\begin{array}{l}\text { Rate of alarm calls per } 10 \mathrm{~h} \text { per } \\
\text { individual }\end{array}$ & \multicolumn{3}{|l|}{0.32} & \multicolumn{2}{|l|}{0.31} & $\mathrm{EBQB}=\mathrm{PI}$ \\
\hline
\end{tabular}

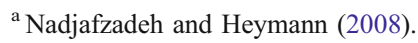

${ }^{\mathrm{b}}$ Personal observation.

position, e.g., when head is turned upside down and eyes are lower than the mouth while being groomed and 2) when an individual is scratching its head in such a way that the head shakes.

We used continuous focal sampling (Martin and Bateson 1990) to record vigilance status (vigilant, not vigilant) and individual activity. We chose the focal individual based on which individuals were visible to maximize the amount of data collected. When there was a choice, we chose the individual with least observations, unless it had been the focal individual during the previous $30 \mathrm{~min}$. Activities were resting (sitting or laying without being engaged in any activity that requires visual attention); feeding/foraging (ingesting food or searching for food using one or both hands to investigate leaves, bark, holes etc.); allogrooming (going through the fur of another individual with the hands; active grooming: activity of the groomer, passive grooming: activity of the groomee); self-grooming (going through own fur with the hands).

Observation conditions allowed for 30-120 s focal observations. Stojan-Dolar entered data directly into a hand-held computer using The Observer Mobile ${ }^{\circledR}$. For each observation we recorded the following variables: individual identity, age class (juvenile: 6-12 mo, subadult: $13-18 \mathrm{mo}$, adult: $>18 \mathrm{mo}$ ), sex (f, m), height (ground, 0-3 m, 3-6 m, 6-9 m, 9-12 m, >12 m), vegetation density $\leq 5 \mathrm{~m}$ above the focal individual (dense: $>70 \%$ of the area covered, medium: $30-70 \%$ covered, thin: $<30 \%$ covered), home range overlap (yes/no), total group size (= number of conspecifics + heterospecifics if present; only individuals $>3$ mo were included), distance to nearest conspecific (touching, 0-3 m, 3-6 m, 6-9 m, 9-12 m, >12 m), number of 
conspecifics $\leq 2 \mathrm{~m}$, distance to nearest heterospecific $(0-3 \mathrm{~m}, 3-6 \mathrm{~m}, 6-9 \mathrm{~m}, 9-12 \mathrm{~m}$, $>12 \mathrm{~m}$ ) and whether the focal individual was carrying an infant. When any of these parameters or individual activity changed during an ongoing observation session, we stopped the session because otherwise it would not have been possible to use the data for an analysis of each of the factors. We considered the 2 species as a MSG when $\geq 1$ individual from each species was $\leq 20 \mathrm{~m}$ (Struhsaker 1981). To ensure independence of observations we never resampled the same individuals within $30 \mathrm{~min}$.

While following the groups, Stojan-Dolar took GPS coordinates every $30 \mathrm{~min}$. We then calculated Minimum Convex Polygons via ArcView to define home ranges and home range overlap areas for each group. Because male and female vigilance in overlap areas could imply different functions, we examined the effect of this variable for males and females separately. Stojan-Dolar also took GPS coordinates of major feeding trees, defined as trees where the group either fed for $\leq 10 \mathrm{~min}$ or returned to at least twice within the same week.

\section{Data Analysis}

For every observation we took the percentage of time spent vigilant as a measure of vigilance. We arcsine transformed percentages before entering them in the analysis (Zar 1999). To avoid pseudoreplication, we analyzed the influence of each independent variable via generalized linear mixed models (GLMM) with individual identity nested within group as a random factor. Owing to the nature of different independent variables, we had to use different data subsets to analyze the effect of individual variables (Table II) and therefore could use only 1-way models. Because individuals at PI did not form MSG, we analyzed group size data separately for MSG at EBQB and for SSG at PI. For distances to heterospecifics, we used only data from EBQB when heterospecifics were present and visible. For infant carrying

Table II Data sets used for analyses of effects of different factors on vigilance

\begin{tabular}{|c|c|c|c|c|}
\hline Factor & Data used & $\begin{array}{l}\text { Number }(\%) \text { of } \\
\text { observations }\end{array}$ & $\begin{array}{l}\text { No. of } \\
\text { individuals }\end{array}$ & $\begin{array}{l}\text { No. of } \\
\text { groups }\end{array}$ \\
\hline No. of conspecifics within $2 \mathrm{~m}$ & All & $2444(100 \%)$ & 44 & 5 \\
\hline Distance to conspecifics & All & $2444(100 \%)$ & 44 & 5 \\
\hline Distance to heterospecifics & $\begin{array}{l}\text { Only MSG at Quebrada Blanco } \\
\text { when heterospecifics visible }\end{array}$ & $1473(60 \%)$ & 21 & 3 \\
\hline Group size in SSG & Only Padre Isla & $810(33 \%)$ & 23 & 2 \\
\hline Total MSG group size & Only MSG at Quebrada Blanco & $1503(62 \%)$ & 21 & 3 \\
\hline Sex & Adults only & $1641(67 \%)$ & 28 & 5 \\
\hline Age & All & $2444(100 \%)$ & 44 & 5 \\
\hline Carrying infants & $\begin{array}{l}\text { Only when infants }<3 \text { mo present } \\
\text { in the group }\end{array}$ & $1591(65 \%)$ & 44 & 5 \\
\hline Height & All & $2444(100 \%)$ & 44 & 5 \\
\hline Vegetation density & All & $2444(100 \%)$ & 44 & 5 \\
\hline Home range overlap & All & $2444(100 \%)$ & 44 & 5 \\
\hline
\end{tabular}


we took data only from the periods when infants were present and visible. In the analyses of all other factors, we used the complete data set.

We conducted separate analyses for each factor and each activity. Of a total of 2444 observations, we made 1449 observations during resting, 721 during feeding, 132 during active grooming (focal individual as groomer), 100 during passive grooming (focal individual as groomee), and 42 during self-grooming. Mustached tamarins often groom very high in the trees and therefore allogrooming sessions are difficult to observe. Thus, the amount of data on vigilance during grooming is much smaller than during resting and feeding. We conducted the analysis for a specific factor only when there were $\geq 10$ observations for each level of the factor. As a consequence, we had to omit some factors from the analysis: total SSG size for vigilance during both active and passive grooming and age, infant carrying, and height for vigilance during passive grooming. We observed self-grooming so rarely that we could not analyze these data further.

\section{Results}

Vigilance levels varied significantly between activities $\left(\operatorname{GLMM}: F_{(4,2416)}=1697.8\right.$, $p<0.001$; Fig. 1) and were highest during resting ( $88.1 \pm 0.3 \%$ ), followed by passive grooming (40.5 $\pm 3.5 \%)$, feeding $(33.2 \pm 0.8 \%)$, self-grooming $(31.8 \pm 3.4 \%)$, and active grooming $(4.4 \pm 0.5 \%)$.

To examine how differences between activities relate to spatial cohesion we checked whether mean number of conspecifics $\leq 2 \mathrm{~m}$ differed with activity. There is a significant difference between activities in the average number of conspecific neighbors (KruskalWallis: $\chi^{2}=663.3$, df $=3, p<0.001$; Fig. 2) and the activity-specific number of neighbors correlates negatively to vigilance level $(r=-0.37, N=2444, p<0.001$, 2-tailed). In this case, we lumped data for active and passive grooming because the groomer and groomee have the same number of neighbors.

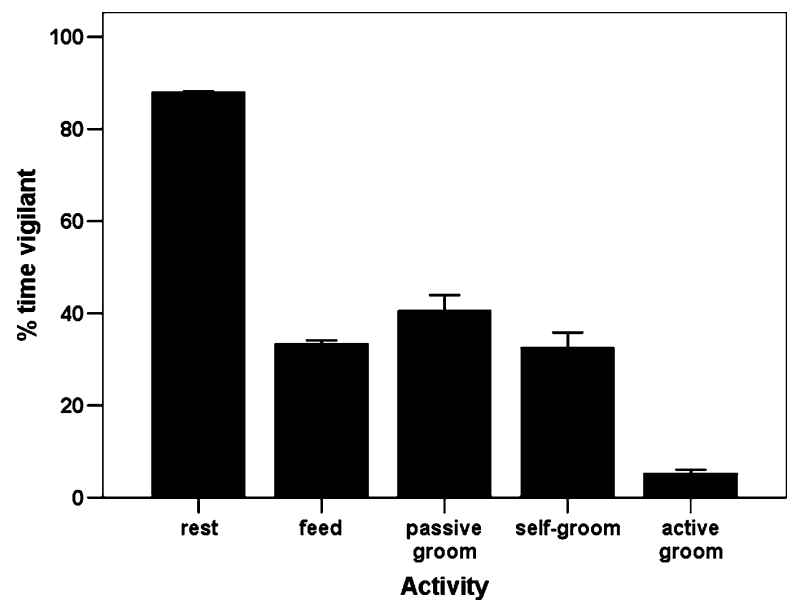

Fig. 1 Mean percentage of time spent vigilant $( \pm$ SE) during different activities. 


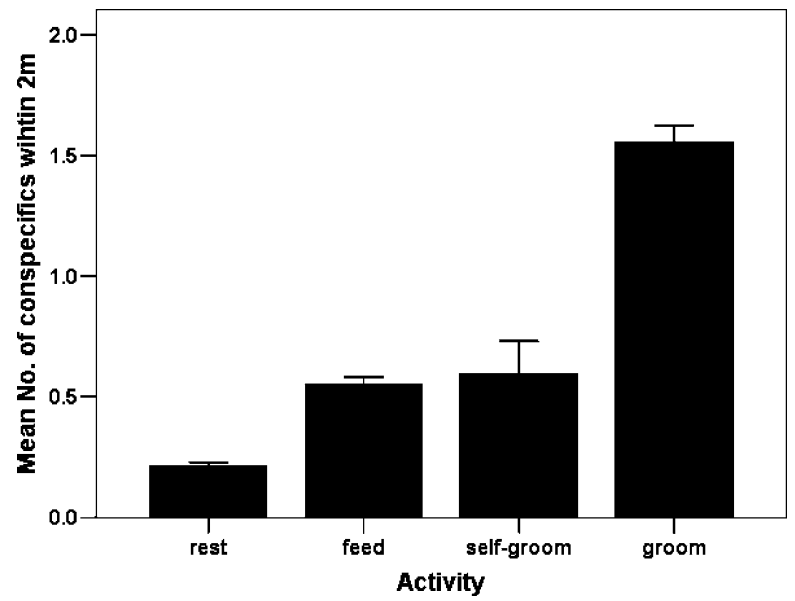

Fig. 2 Mean number of conspecifics within $2 \mathrm{~m}( \pm \mathrm{SE})$ during different activities.

During feeding, subjects at EBQB were more vigilant (39.1 $\pm 1.1 \%$ of time) than those at PI $\left(26.5 \pm 1.0 \%\right.$ of time; GLMM: $F_{(1,38)}=48.4, p<0.001$; Fig. 3$)$. Therefore we divided feeding data by site in further analyses. There are no differences between the sites in vigilance during other activities (GLMM, resting: $F_{(1,39)}=0.9$, n.s.; passive grooming: $F_{(1,91)}=0.1$, n.s.; active grooming: $F_{(1,132)}=0.01$, n.s.).

Vigilance was influenced by different sets of factors during different activities (Table III; Figs. 4 and 5). During resting, vigilance decreased with total MSG size,

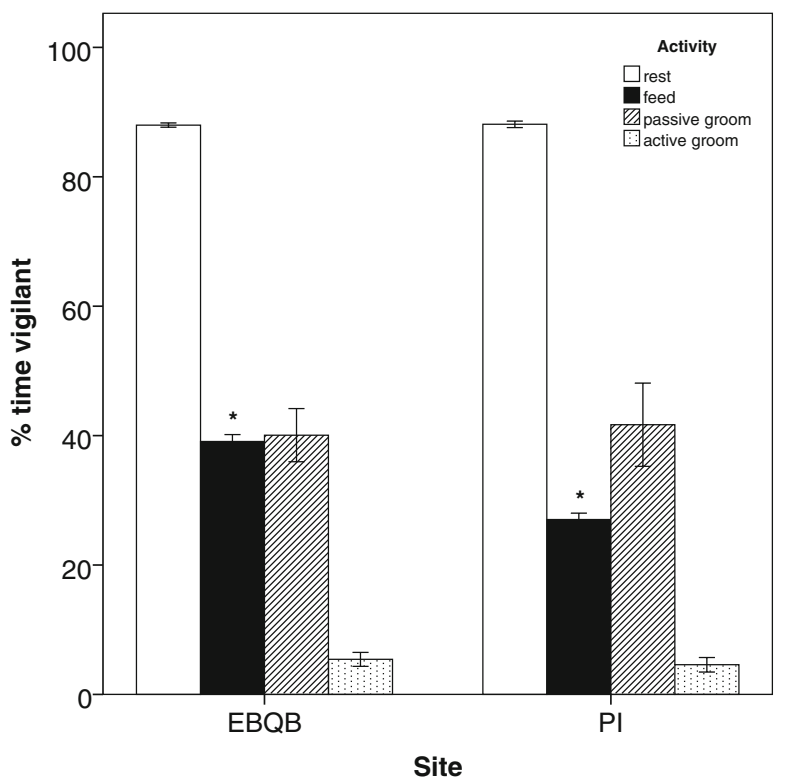

Fig. 3 Comparison of vigilance during different activities between the 2 study sites. Error bars represent SE. * Statistically significant at $p<0.05$. 
increased with infant carrying, and first decreased, then increased with height. During feeding, vigilance decreased with the presence of conspecific neighbors and increased with distance to conspecifics and distance to heterospecifics. There were also differences between the sites. At PI, but not at EBQB, vigilance during feeding was higher in home range overlap areas for both sexes. At EBQB, but not at PI, vigilance during feeding increased with height and males were more vigilant than females. Higher male vigilance could imply social vigilance due to increased intrasexual competition as a result of a higher male/female ratio at EBQB. In this case, males at EBQB would not decrease their vigilance in the proximity of neighbors. This was not the case: both males and females were less vigilant if they had neighbors $\leq 2 \mathrm{~m}$ (GLMM, males: $F_{(3,212)}=6.4, p<0.001$, females: $\left.F_{(3,154)}=5.1, p<0.001\right)$ and if nearest neighbor was closer (males: $F_{(4,210)}=4.4, p<0.001$, females: $F_{(3,141)}=2.9$, $p<0.05)$. Vigilance during passive grooming was influenced only by vegetation density and was highest at places with medium cover density. During active grooming vigilance was not influenced by any of the factors included in the analysis.

\section{Discussion}

\section{Factors Affecting Vigilance}

At both sites, vigilance was most strongly affected by factors related to group cohesion: number of neighbors $\leq 2 \mathrm{~m}$ and distance to conspecifics and heterospecifics. The group size effect was considerably smaller and was significant only during resting. Other researchers have found a group size effect in MSG of birds (Lima 1995; Metcalfe 1984b; Popp 1988; Sullivan 1984) and gazelles (Fitzgibbon 1990), but studies on MSG of primates have yielded mixed results: individual vigilance increased, decreased, or did not change with increasing group size (Chapman and Chapman 1996; Cords 1990; Hardie and Buchanan-Smith 1997; Treves 1999).

Our results suggest that although the effect of group size is weaker than that of neighbors, both factors influence vigilance in wild mixed-species groups of tamarins but they operate in different behavioral contexts. Most researchers did not consider that vigilance during different activities might be influenced by different variables (cf. Blumstein 1996; Chalmeau et al. 1998), which may explain why the group size effect was not always detected. Detecting a group size effect during resting may also contribute to the resolution of the question of whether decreased individual vigilance in larger groups is a result of predation effects or scramble competition (Beauchamp 2003). If the group size effect appears in other behavioral contexts than feeding it is unlikely to be related to food competition (Arenz 2003).

Heterospecifics appear to have an important role in antipredator behavior of tamarins in MSG, which is in line with the hypothesis that predation is a major evolutionary cause for MSG formation (Fitzgibbon 1990; Munn 1986; Noë and Bshary 1997; Struhsaker 1981; Terborgh 1990). Saddleback tamarins contributed to the group-size effect and mustached tamarins decreased their vigilance in proximity of conspecifics as well as heterospecifics.

Surprisingly, group size had no effect in SSG on PI, where groups are unusually large (8-14 versus 5-9 individuals of Saguinus mystax in MSG at EBQB). The 


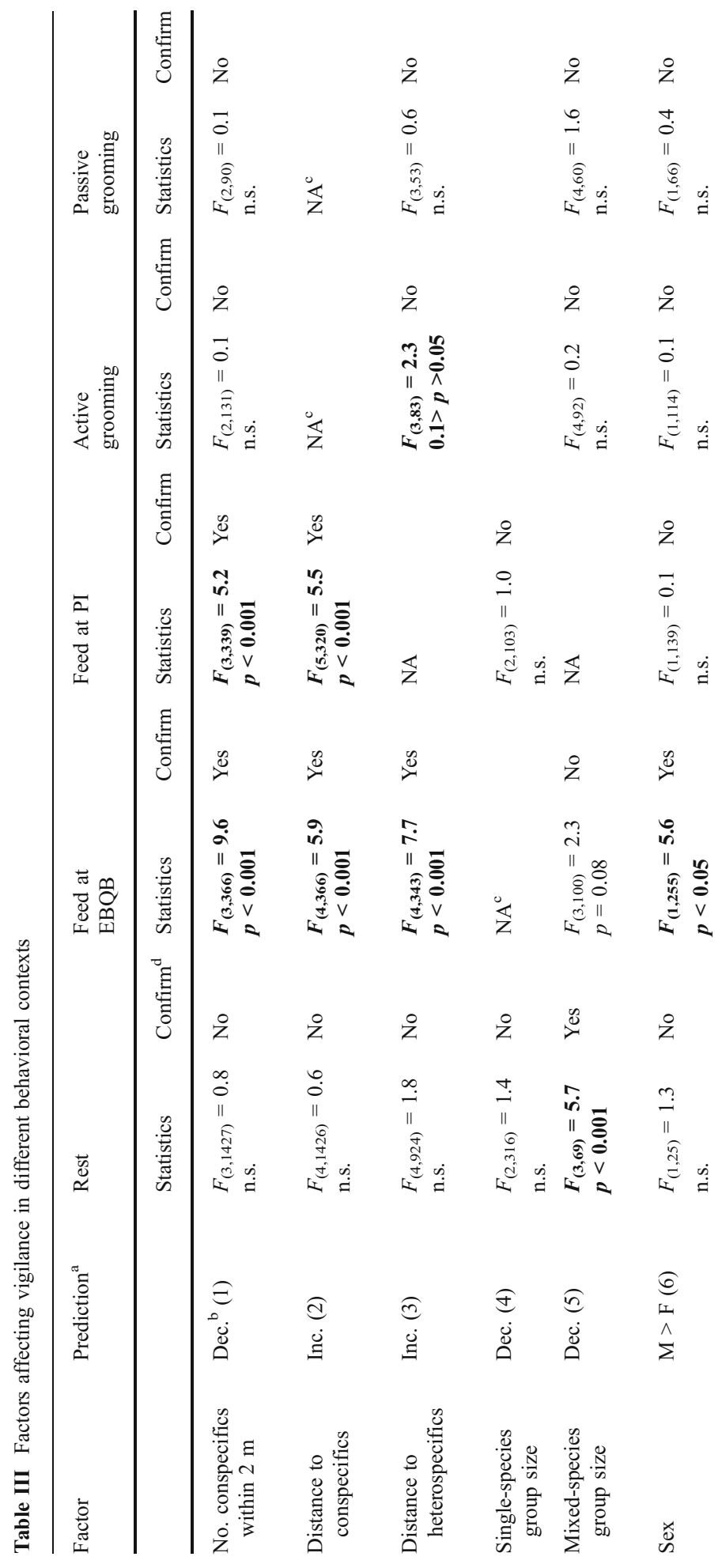




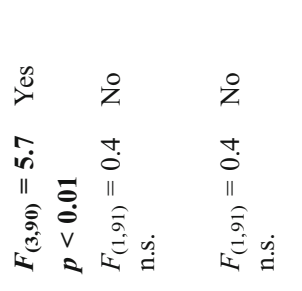

z z z z z

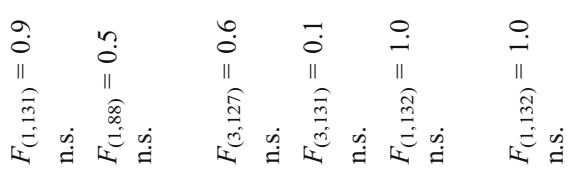

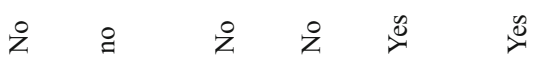

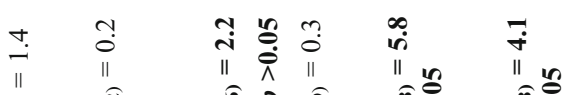

ㄱ. तิ

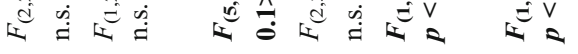

z z $\stackrel{0}{0}$ z

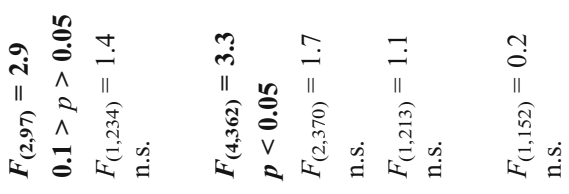

过.

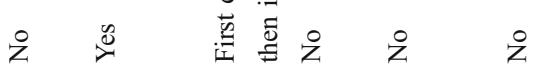

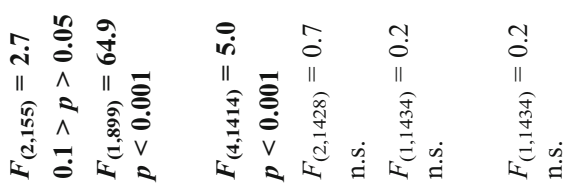

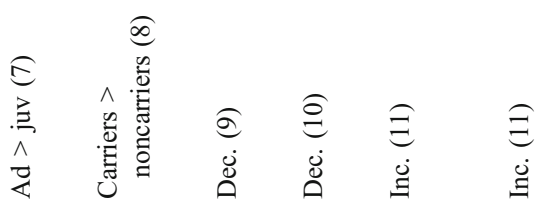

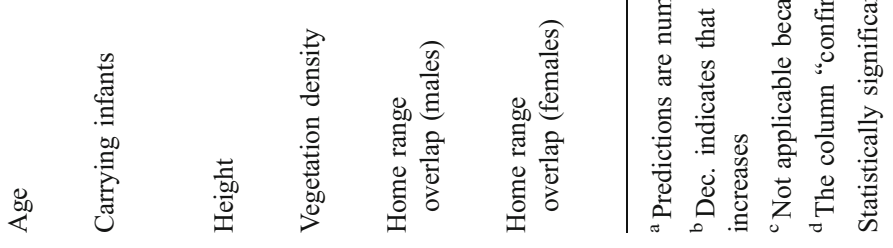


absence of the group-size effect in unusually large SSG could be attributed to social vigilance, which could increase to the point that the slight decrease in antipredator vigilance detected in MSG is canceled out.

Adult males at EBQB, but not at PI, were more vigilant when feeding than adult females. This sex difference has been observed in a number of other studies (Burger and Gochfeld 1994; Goldizen 1989; Price et al. 1991). Males might contribute higher levels of antipredator vigilance as a trade-off for group membership (van Schaik and van Noordwijk, 1989; Yáber and Herrera, 1994) or due to increased intrasexual competition at EBQB where male/female ratio was higher as at PI. However, in the latter case male-male aggression should be higher than within other dyads, which is not supported in the literature (Huck et al. 2004b), and the effect of neighbors should be weaker for males than for females, which was also not the case.

The effect of height on vigilance during resting contradicted our prediction. Subjects first slightly decreased their vigilance with increasing height and then again increased their vigilance at higher levels of the forest. This differs from most other studies, which showed that arboreal primates subjected to predation by raptors increase their vigilance at lower levels of the forest (Hirsch 2002; Smith et al. 2004; Steenbeek et al. 1999; Treves 2002; van Schaik and van Noordwijk 1989). Our data partially support the notion that lower heights are perceived as more dangerous because mustached tamarins descended to the ground only to feed and never groomed $<3 \mathrm{~m}$. However, the observed vigilance patterns indicate that intermediate heights are actually perceived as safest. Close to the ground, there might be a combined risk of attacks by raptors and terrestrial predators, whereas high in the canopy increased caution might be needed owing to potential proximity of raptors. The unexpected increase of vigilance with height might also emerge because individuals are increasingly difficult to observe at higher levels and therefore these results might be less robust than the results for other height classes.

Vegetation density influenced vigilance only during passive grooming. The groomees in our study responded very flexibly to potential exposure to predators by dedicating anything between 0 and $97 \%$ of time to vigilance, whereas vigilance during other activities was far less variable. Their vigilance was often very low or zero in areas with either thin or dense vegetation cover, but increased considerably at spots with intermediate vegetation density. Although this result contradicts our prediction and findings from other primate studies (Boinski et al. 2003; Cords 1990), it is in line with the idea that vegetation can act as both protective and obstructive cover (Arenz and Leger, 1997a, 1997b; Lazarus and Symonds, 1992). Some species or populations may prefer the option to detect a predator more easily over being hidden in dense vegetation (Metcalfe 1984a; Treves 2002).

Monkeys at PI, but not at EBQB, increased their vigilance in home range overlap areas. Because this increase only occurred when feeding and both sexes behaved in

Fig. 4 Factors affecting vigilance during $(\circ)$ resting, $(\diamond)$ feeding at EBQB, $(\diamond)$ feeding at PI, ( $\square$ ) passive grooming, and ( $\square$ ) active grooming. Graphs represent the effects of (a) number of conspecifics $\leq 2 \mathrm{~m}$; (b) distance to conspecifics; (c) distance to heterospecifics; (d) total single-species group size; (e) total mixedspecies group size; (f) age; (g) height of the focal individual; and (h) vegetation density. Statistically significant $(p<0.05)$ effects are shown in black. Error bars represent SE. *Statistically significant at $p<0.05$ (Bonferroni pairwise comparisons). 


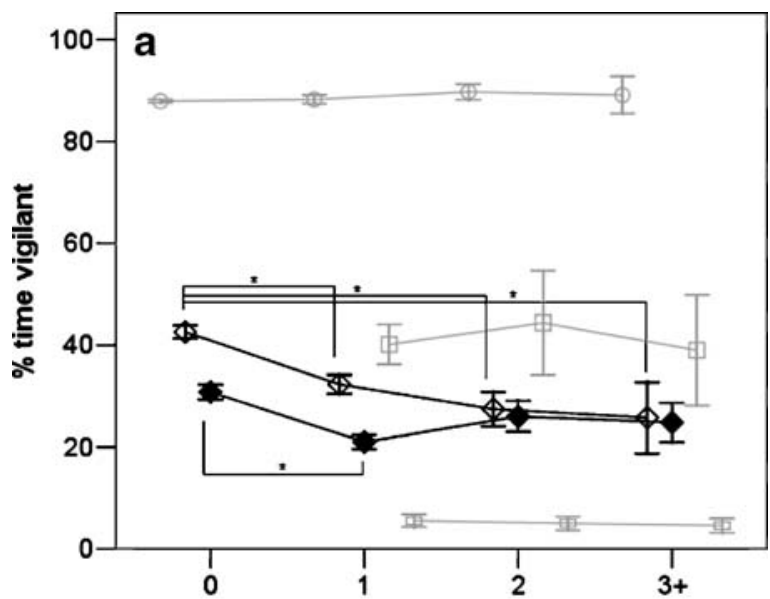

No. of conspecifics within $2 \mathrm{~m}$
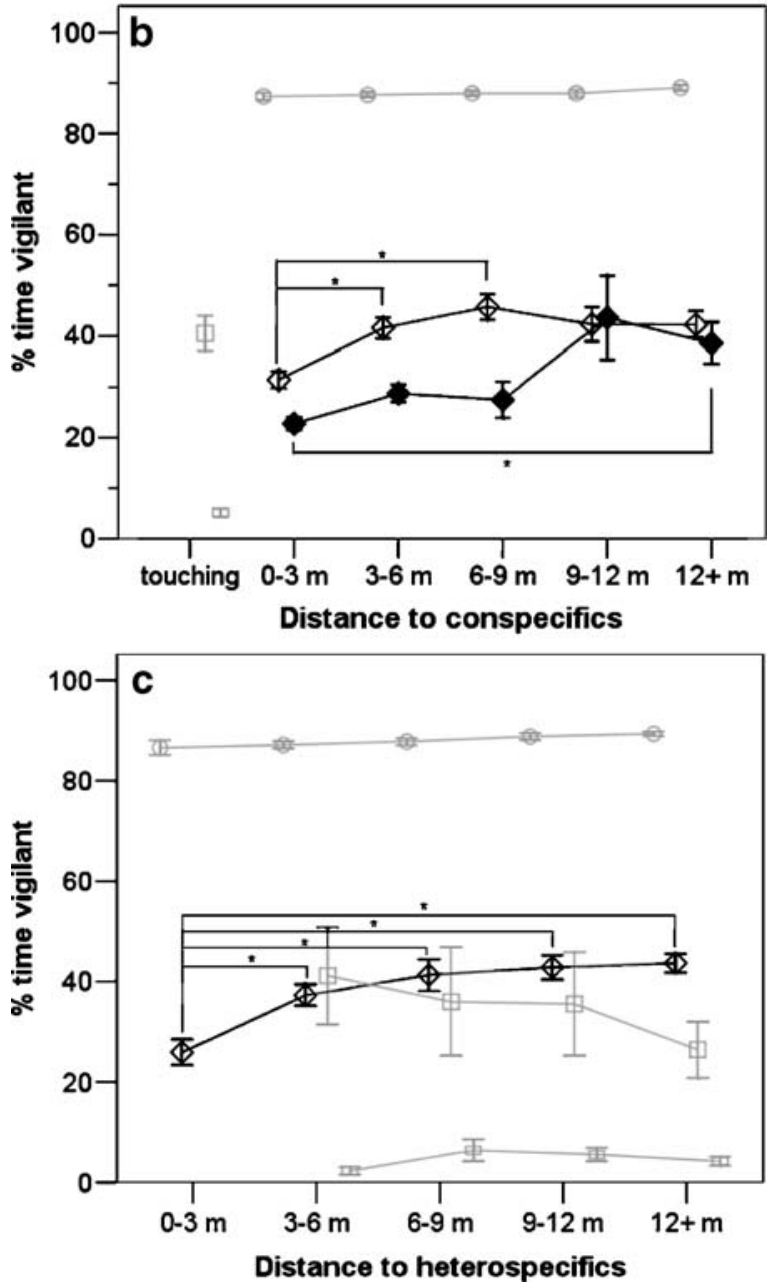

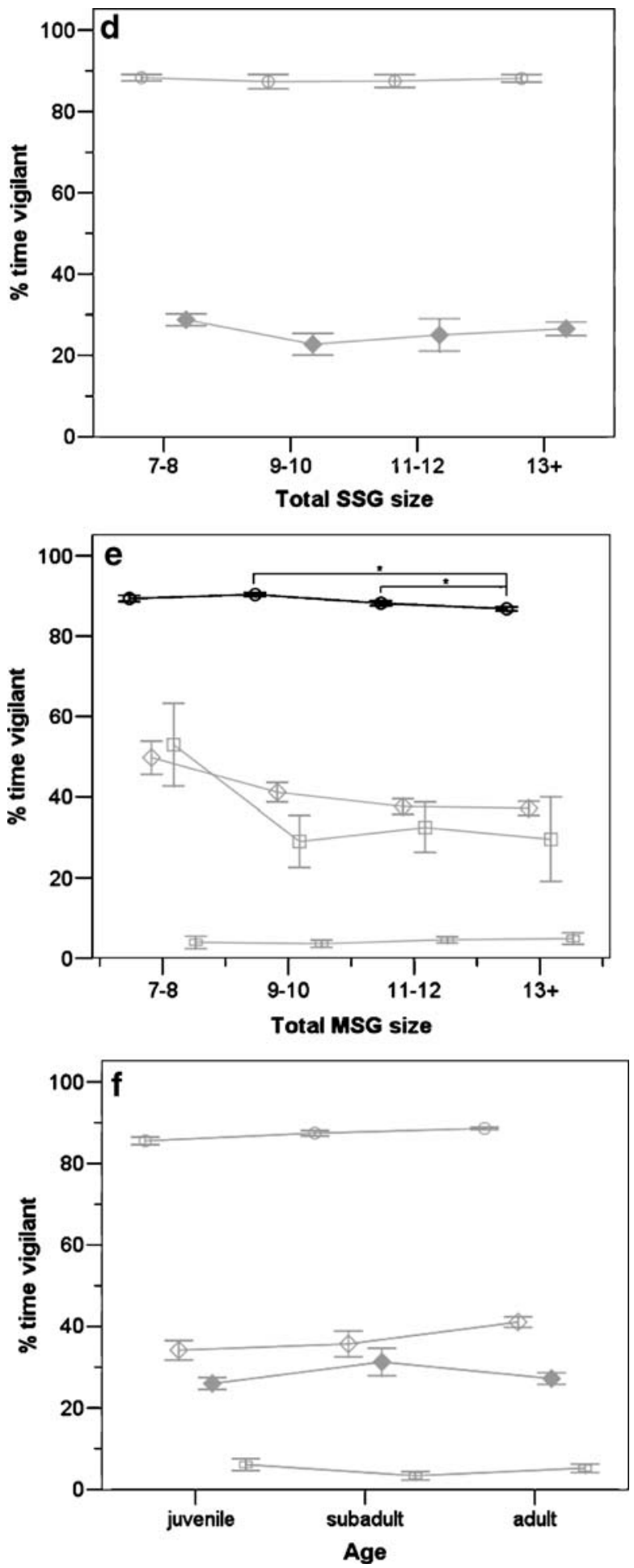

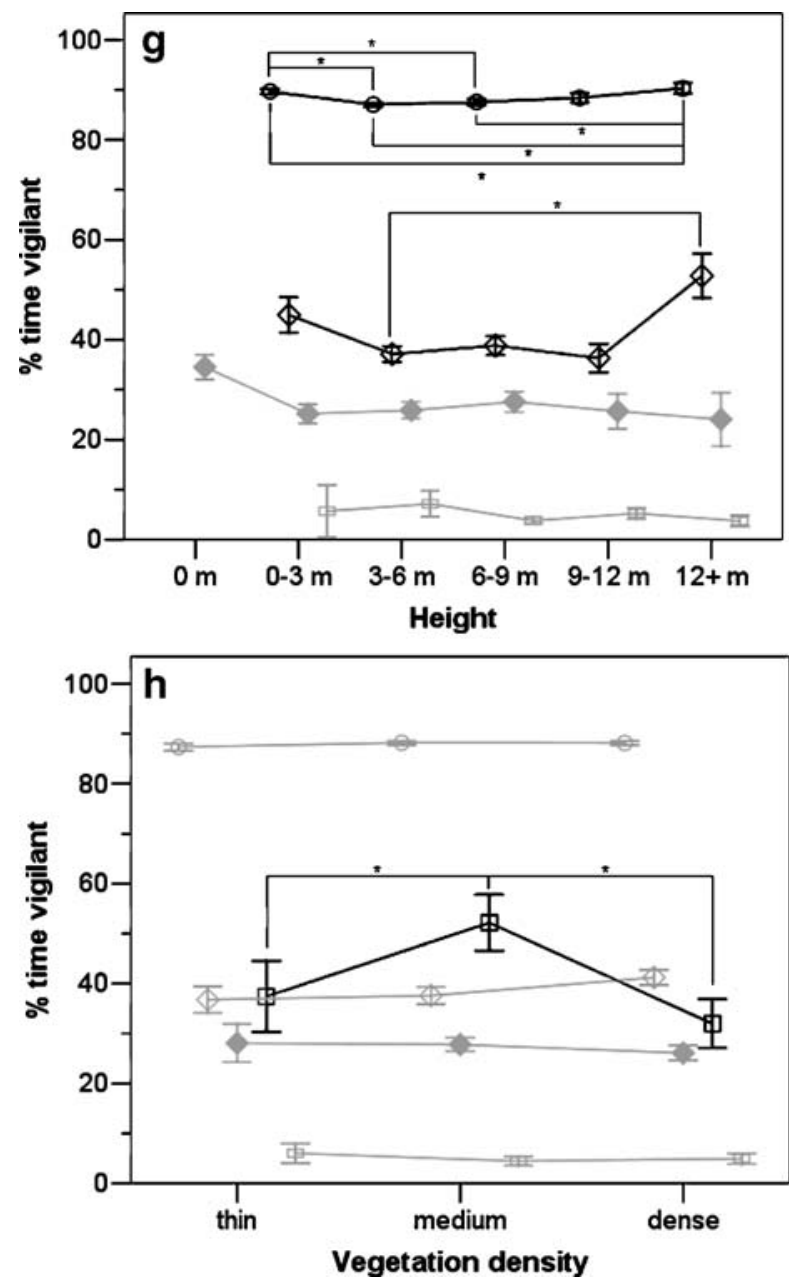

the same way, we can conclude that it is probably due to resource defense. But as the difference in vigilance was more pronounced in males than females, mate defense might also play a role. Garber et al. (1993) also found indications for both resource and mate defense in the PI population. In both cases the same increase of vigilance could be theoretically expected also at EBQB but the demographic and ecological differences between the sites may explain why vigilance in overlap areas only increased at PI. Higher population density in combination with smaller home ranges at PI leads to a higher probability of intergroup encounters, which may make monkeys more attentive in the overlap areas. Further, groups at PI are larger but have a smaller number of feeding trees in their home ranges. This probably makes the trees in the overlap areas more valuable and therefore resource defense might be more important than at EBQB. 

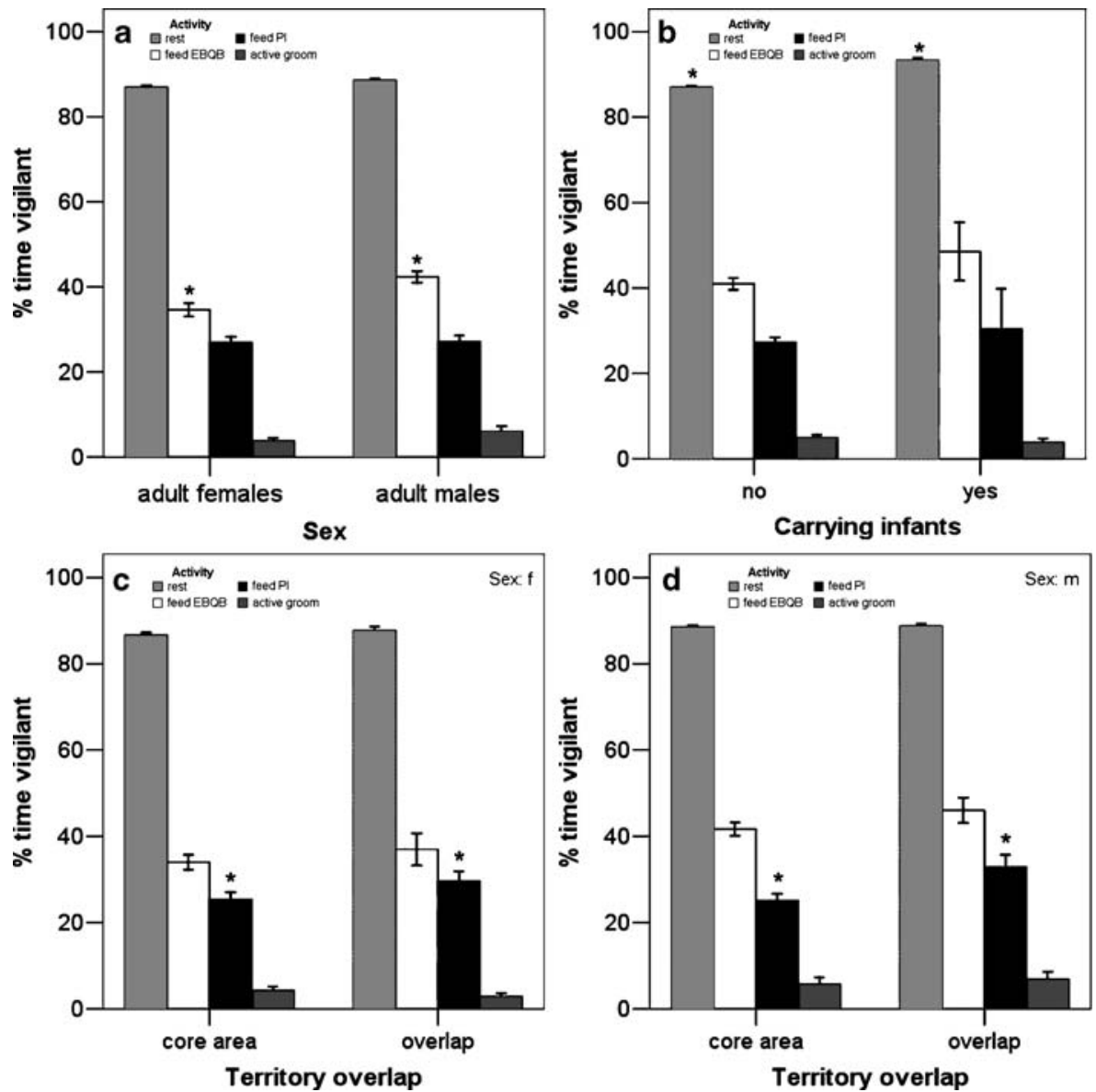

Fig. 5 Effects of (a) sex; (b) infant carrying; (c) home range overlap for females; and (d) home range overlap for males on vigilance. Error bars represent SE. * Statistically significant at $p<0.05$ (Bonferroni pairwise comparisons).

\section{Vigilance in Relation to Other Activities}

Vigilance patterns differed greatly depending on behavioral context. Mustached tamarins were considerably more vigilant during resting than during feeding, passive grooming or self-grooming and $c a .20$ times more vigilant during resting than during active grooming. Researchers have also found a decrease of vigilance in the order rest-feed-groom in other primates (Cords 1995; Cowlishaw 1998; Hirsch 2002; van Schaik and van Noordwijk 1989) although the magnitude of differences can vary considerably between species, e.g., Papio cynocephalus: $15-25 \%$ during feeding, 50-60\% during resting; Pan troglodytes: 4\% during feeding, 40\% during resting.

Vigilance levels during resting were very high, probably because the costs of being vigilant while resting are minimal. Resting could be seen as the activity with baseline levels of vigilance, i.e., how vigilant individuals would be if there were no trade-offs between vigilance and the concurrent activity. This can serve in cross- 
population or cross-species comparisons as an estimate of the differences in perceived predation risk, which is otherwise difficult to measure directly. Because individuals probably prefer relaxed resting without continuous head movements, it can be expected that species or populations with lower predation risk show lower levels of vigilance than those with higher predation risk. Applying this reasoning to our study, we can conclude that the alarm-call-based estimate that there was no difference in perceived predation risk between populations at EBQB and PI was correct; levels of vigilance when resting also did not differ.

Feeding and foraging represent $15-40 \%$ of the active time of mustached tamarins (Castro Coronado 1991; Garber 1993; Huck et al. 2004a). During this time, they spent on average $39.1 \%$ (EBQB) and $26.5 \%$ (PI) of time vigilant. The difference between the sites could stem from the differences in the diet. At PI monkeys rely almost entirely on fruit (Stojan-Dolar and Heymann, pers. obs.), which requires a large amount of visual attention because fruits need to be picked continuously from the tree, and some fruits are difficult to open and require much handling. Feeding on fruits was also often done in a position that is completely incompatible with vigilance, e.g., upside-down. Conversely, insects, require less visual attention because no special manipulation is needed once they have been caught. Alternatively, lower vigilance at PI could indicate that predation pressure there was lower despite the same rate of alarm calls. However, in this case vigilance during other activities should also be lower at PI, which was not the case.

During active allogrooming subjects were considerably less vigilant than during feeding, which is interesting because allogrooming is presumably far less important for survival than feeding. Researchers have shown low vigilance levels in groomers also in other species (Cords 1995; Maestripieri 1993; Mooring and Hart 1995). This is certainly important as a potential fitness cost that affects the cost/benefit ratio of grooming behavior. Very low vigilance levels during active allogrooming are possible also because there is always $\geq 1$ conspecific neighbor in close proximity, which enhances the dilution effect, and because groomees are on average about 6 times more vigilant than groomers.

Not only did individual vigilance change during different activities, but vigilance was also affected by different sets of factors in different behavioral contexts. We propose 3 possible explanations that are not mutually exclusive. First, group spread changes with different activities and this could influence whether neighbors or group size affects vigilance. The effect of neighbors weakens at distances $>3 \mathrm{~m}$, which means that when the group is spread out the nearest neighbor probably does not have much effect on vigilance levels. During resting, individuals were less congregated so the total group size might have been more important than neighbors. During feeding, the subjects were more likely to have a neighbor in close proximity, and the influence of neighbors was stronger than that of the total group size.

Second, the magnitude of predation risk might vary with activity. Grooming is a very stationary activity and therefore predation risk is probably defined by vegetation density to a much greater extent than in activities where monkeys frequently change location. In contrast, feeding could occur at more dangerous spots than other activities because individuals have to go where food is (Cords 1990).

Third, different activities allow different amounts of time for vigilance. A pattern emerging from our study is that activities with either very low or very high vigilance 
levels are affected by a smaller number of factors than activities with intermediate vigilance levels (Table III). During resting, the opportunity cost is low and vigilance was always very high. Even when significant effects were detected, they were not of large magnitude. In contrast, during active allogrooming, vigilance was always low and not affected by any of the factors we measured. The invariance of vigilance levels in this case might occur because vigilance can neither increase -due to its incompatibility with active allogrooming- nor decrease because it is already at minimum. During feeding, vigilance levels were intermediate and the trade-off between vigilance and feeding could be more flexibly adjusted. In the few existing studies that separately analyzed vigilance by activity there is some support for the prediction that vigilance during feeding/foraging is affected by more factors than during other activities (Bshary and Noë 1997; Chalmeau et al. 1998). The exception to this pattern is vigilance during passive allogrooming, which was at about the same level as during feeding but was nevertheless affected only by 1 factor. However, due to limited data on passive allogrooming we could only run the analysis for 7 factors, out of which further three (distance to nearest conspecific, number of conspecifics $\leq 2 \mathrm{~m}$, and distance to nearest heterospecific) are not relevant. Therefore, only 4 factors could be expected to change for vigilance during passive allogrooming (vegetation density, MSG size, sex, and home range overlap).

\section{The Function of Vigilance}

Our results indicate that scanning for predators is the predominant function of vigilance in mustached tamarins, which was expected due to relatively high predation pressure on one hand and relatively low rates of intragroup aggression on the other. Vigilance decreased in situations where detection and dilution effects were stronger, i.e., in proximity of conspecifics and heterospecifics and in larger MSG. It was also affected by height and vegetation density, which are both factors that very likely influence animals' perception of predation risk.

There was no evidence that mustached tamarins monitor their group mates to avoid food stealing or aggression. In fact, they decreased their vigilance in proximity of conspecifics only during feeding, although having another group member in vicinity while feeding is the situation when increased vigilance against conspecifics could be expected. Mustached tamarins are also unlikely to be vigilant to avoid aggression because intragroup aggression rates are very low (Heymann 1996; Huck et al. 2004b).

Individuals monitor other group members also to maintain group cohesion. To some extent this function of vigilance would be difficult to disentangle from antipredator vigilance because in both cases we would observe decreased vigilance in proximity of neighbors, but monitoring group members should increase, not decrease with group size. The absence of the group size effect when in unusually large SSG therefore provides support for this function of vigilance that is probably less important in average-sized groups.

In the PI population with higher population density both, males and females increased vigilance in overlap areas, which implies that vigilance also serves detection of neighboring groups. However, it appears that at EBQB, where intergroup encounters are less probable and home ranges are larger, vigilance is not directed at neighboring groups. 
Further, mate guarding and infanticide avoidance are also plausible functions of vigilance in many species. Unfortunately, we were not able to observe mate guarding during female receptive periods owing to the rotation of observations between the groups. Infanticide is very rare in callitrichids, and when it occurs it is the mother or the subordinate female that kills the infant (Digby 1995; Roda and Pontes 1998; Tirado Herrera et al. 2000). It is unlikely that other group members would be vigilant against the infant's own mother since she is most closely related to the infant and would be expected to have strongest interest in infant survival.

In sum, vigilance is a complex phenomenon that serves several functions and depends on many different factors, and vigilance studies therefore demand careful interpretation.

\section{Conclusions}

- Vigilance levels are affected by different factors in different behavioral contexts. One should take this into account when investigating vigilance behavior and analyses should preferably be separated by activity.

- Predator detection and avoidance seems to be the predominant function of vigilance in mustached tamarins, but a part of visual scanning is probably also dedicated to maintaining group cohesion and monitoring neighboring groups.

- The presence of heterospecifics in MSG of tamarins enables individuals to decrease their vigilance when feeding and contributes to the group size effect when resting, which supports the notion that collective vigilance against predators is an important incentive in the evolution of these MSG.

- Comparison of vigilance behavior between different populations of the same species allows for an examination of factors that can otherwise not be considered (population density, home range size, diet), but appear to influence vigilance and consequently the costs and benefits of group living.

\footnotetext{
Acknowledgments We thank the following people and organizations: Instituto Veterinario de Investigaciones Tropicales y de Altura (IVITA) for permission to work at the biological station on Padre Isla; our field assistants Camilo Flores Amasifuen, Ney Shahuano Tello, and Manuel Shahuano Tello for their invaluable help in the forest; Carlos Ique for helpful practical advice; Prof. Walter Zucchini for patient help with statistics; and Vanessa Mass and Markus Port for helpful discussions and suggestions. The manuscript benefited greatly from helpful advice from 4 anonymous reviewers. Financial support was partially provided by Deutscher Akademischer Austausch Dienst (DAAD). Field work was authorized by the Instituto Nacional de Recursos Naturales (authorization no. 018-2006-INRENA-IFF_DCB) and complied with Peruvian laws.
}

Open Access This article is distributed under the terms of the Creative Commons Attribution Noncommercial License which permits any noncommercial use, distribution, and reproduction in any medium, provided the original author(s) and source are credited.

\section{References}

Arenz, C. L., \& Leger, D. W. (1997a). The antipredator vigilance of adult and juvenile thirteen-lined ground squirrels (Sciuridae: Spermophilus tridecemlineatus): Visual obstruction and simulated hawk attacks. Ethology, 103, 945-953. 
Arenz, C. L., \& Leger, D. W. (1997b). Artificial visual obstruction, antipredator vigilance, and predator detection in the thirteen-lined ground squirrel (Spermophilus tridecemlineatus). Behaviour, 134, 1101-1114.

Arenz, C. R. (2003). The group size effect on vigilance: Many unanswered questions. Behavioural Processes, 63, 123-124.

Bachman, G. C. (1993). The effect of body condition on the trade-off between vigilance and foraging in belding ground-squirrels. Animal Behaviour, 46, 233-244.

Beauchamp, G. (2003). Group-size effects on vigilance: A search for mechanisms. Behavioural Processes, $63,111-121$.

Blumstein, D. T. (1996). How much does social group size influence golden marmot vigilance? Behaviour, 133, 1133-1151.

Blumstein, D. T., Daniel, J. C., \& Evans, C. S. (2001). Yellow-footed rock-wallaby group size effects reflect a trade-off. Ethology, 107, 655-664.

Boinski, S., Kauffman, L., Westoll, A., Stickler, C. M., Cropp, S., \& Ehmke, E. (2003). Are vigilance, risk from avian predators and group size consequences of habitat structure? A comparison of three species of squirrel monkey (Saimiri oerstedii, S. boliviensis, and S. sciureus). Behaviour, 140, 1421-1467.

Bshary, R., \& Noë, R. (1997). Red colobus and Diana monkeys provide mutual protection against predators. Animal Behaviour, 54, 1461-1474.

Burger, J., \& Gochfeld, M. (1994). Vigilance in African mammals - Differences among mothers, other females, and males. Behaviour, 131, 153-169.

Caine, N. G. (1984). Visual scanning by tamarins: A description of the behavior and tests of two derived hypotheses. Folia Primatologica, 43, 59-67.

Caine, N. G., \& Marra, S. L. (1988). Vigilance and social organization in two species of primates. Animal Behaviour, 36, 897-904.

Caro, T. (2005). Antipredator defenses in birds and mammals. Chicago: The University of Chicago Press.

Castro Coronado, N. R. (1991). Behavioral ecology of two coexisting tamarin species (Saguinus fuscicollis nigrifrons and Saguinus mystax mystax, Callitrichidae, Primates) in Amazonian Peru. $\mathrm{PhD}$ thesis. Washington University, St. Louis.

Chalmeau, R., Cezilly, F., \& Desportes, J. (1998). Vigilance during foraging and allogrooming in semifree-ranging Barbary macaques. Folia Primatologica, 69, 381-385.

Chapman, C. A., \& Chapman, L. J. (1996). Mixed-species primate groups in the Kibale Forest: Ecological constraints on association. International Journal of Primatology, 17, 31-50.

Childress, M. J., \& Lung, M. A. (2003). Predation risk, gender and the group size effect: Does elk vigilance depend upon the behaviour of conspecifics? Animal Behaviour, 66, 389-398.

Cords, M. (1990). Vigilance and mixed-species association of some East African forest monkeys. Behavioral Ecology and Sociobiology, 26, 297-300.

Cords, M. (1995). Predator vigilance costs of allogrooming in wild blue monkeys. Behaviour, 132, 559569.

Cowlishaw, G. (1998). The role of vigilance in the survival and reproductive strategies of desert baboons. Behaviour, 135, 431-452.

de A. Moura, A. C., \& Alonso, C. (2000). Sex and age differences in foraging and vigilance behavior of captive Saguinus midas midas (Primates: Callitrichidae). A Primatologia no Brasil, 7, 223-238.

Di Blanco, Y., \& Hirsch, B. T. (2006). Determinants of vigilance behavior in the ring-tailed coati (Nasua nasua): The importance of within-group spatial position. Behavioral Ecology and Sociobiology, 61, $173-182$.

Digby, L. (1995). Infant care, infanticide, and female reproductive strategies in poygynous groups of common marmosets (Callithrix jacchus). Behavioral Ecology and Sociobiology, 37, 51-61.

Elgar, M. A. (1989). Predator vigilance and group size in mammals and birds: A critical review of the empirical evidence. Biological Reviews of the Cambridge Philosophical Society, 64, 13-33.

Fitzgibbon, C. D. (1990). Mixed-species grouping in Thomson and Grant gazelles - the antipredator benefits. Animal Behaviour, 39, 1116-1126.

Garber, P. A. (1988). Diet, foraging patterns, and resource defense in a mixed species troop of Saguinus mystax and Saguinus fuscicollis in Amazonian Peru. Behaviour, 105, 18-34.

Garber, P. A. (1993). Seasonal patterns of diet and ranging in two species of tamarin monkeys - stability versus variability. International Journal of Primatology, 14, 145-166.

Garber, P. A. (1997). One for all and breeding for one: Cooperation and competition as a tamarin reproductive strategy. Evolutionary Anthropology, 5(6), 187-199.

Garber, P. A., Pruetz, J. D., \& Isaacson, J. (1993). Patterns of range use, range defense, and intergroup spacing in moustached tamarin monkeys (Saguinus mystax). Primates, 34, 11-25. 
Goldizen, A. (1989). Social relationships in a cooperatively polyandrous group of tamarins (Saguinus fuscicollis). Behavioral Ecology and Sociobiology, 24, 79-89.

Hamilton, W. D. (1971). Geometry for the selfish herd. Journal of Theoretical Biology, 31, $295-311$.

Hardie, S. M., \& Buchanan-Smith, H. M. (1997). Vigilance in single- and mixed-species groups of tamarins (Saguinus labiatus and Saguinus fuscicollis). International Journal of Primatology, 18, 217-234.

Heymann, E. W. (1990a). Reactions of wild tamarins, Saguinus mystax and Saguinus fuscicollis to avian predators. International Journal of Primatology, 11, 327-337.

Heymann, E. W. (1990b). Social behaviour and infant carrying in a group of moustached tamarins, Saguinus mystax (Primates: Platyrrhini: Callitrichidae), on Padre Isla, Peruvian Amazonia. Primates, 31, 183-196.

Heymann, E. W. (1996). Social behavior of wild moustached tamarins, Saguinus mystax, at the Estacion Biologica Quebrada Blanco, Peruvian Amazonia. American Journal of Primatology, 38, 101-113.

Heymann, E. W., \& Buchanan-Smith, H. M. (2000). The behavioural ecology of mixed-species troops of callitrichine primates. Biological Reviews of the Cambridge Philosophical Society, 75, 169-190.

Hill, R. A., \& Dunbar, R. I. M. (1998). An evaluation of the roles of predation rate and predation risk as selective pressures on primate grouping behaviour. Behaviour, 135, 411-430.

Hirsch, B. T. (2002). Social monitoring and vigilance behavior in brown capuchin monkeys (Cebus apella). Behavioral Ecology and Sociobiology, 52, 458-464.

Huck, M., Löttker, P., Bohle, U. R., \& Heymann, E. W. (2005). Paternity and kinship patterns in polyandrous moustached tamarins (Saguinus mystax). American Journal of Physical Anthropology, 127, 449-464.

Huck, M., Löttker, P., \& Heymann, E. W. (2004a). The many faces of helping: Possible costs and benefits of infant carrying and food transfer in wild moustached tamarins (Saguinus mystax). Behaviour, 141, 915-934.

Huck, M., Löttker, P., \& Heymann, E. W. (2004b). Proximate mechanisms of reproductive monopolization in male moustached tamarins (Saguinus mystax). American Journal of Primatology, 64, 39-56.

Ique, C. (2000). Manejo semi-extensivo de Saguinus mystax en Padre Isla, río Amazonas. In F. Howard \& M. García Podestá (Eds.), La Primatología en el Perú 2 (pp. 131-143). Lima: Master Graf Editores.

Isbell, L. A., \& Young, T. P. (1993). Social and ecological influences on activity budgets of vervet monkeys, and their implications for group living. Behavioral Ecology and Sociobiology, 32, 377-385.

Kutsukake, N. (2006). The context and quality of social relationships affect vigilance behaviour in wild chimpanzees. Ethology, 112, 581-591.

Lazarus, J., \& Symonds, M. (1992). Contrasting effects of protective and obstructive cover on avian vigilance. Animal Behaviour, 43, 519-521.

Lima, S. L. (1995). Back to the basics of antipredatory vigilance: The group size effect. Animal Behaviour, 49, 11-20.

Lima, S. L., Zollner, P. A., \& Bednekoff, P. A. (1999). Predation, scramble competition, and the vigilance group size effect in dark-eyed juncos (Junco hyemalis). Behavioral Ecology and Sociobiology, 46, 110-116.

Löttker, P., Huck, M., \& Heymann, E. W. (2004). Demographic parameters and events in wild moustached tamarins (Saguinus mystax). American Journal of Primatology, 64, 425-449.

Maestripieri, D. (1993). Vigilance costs of allogrooming in macaque mothers. American Naturalist, 141, $744-753$.

Martin, P., \& Bateson, P. (1990). Measuring behaviour - an introductory guide. Cambridge: Cambridge University Press.

Metcalfe, N. B. (1984a). The effects of habitat on the vigilance of shorebirds - Is visibility important? Animal Behaviour, 32, 981-985.

Metcalfe, N. B. (1984b). The effects of mixed-species flocking on the vigilance of shorebirds: Who do they trust? Animal Behaviour, 32, 986-993.

Mooring, M. S., \& Hart, B. L. (1995). Costs of allogrooming in impala: Distraction from vigilance. Animal Behaviour, 49, 1414-1416.

Munn, C. A. (1986). Birds that cry wolf. Nature, 319, 143-145.

Nadjafzadeh, M., \& Heymann, E. W. (2008). Prey foraging of red titi monkeys, Callicebus cupreus, in comparison to sympatric tamarins, Saguinus mystax and Saguinus fuscicollis. American Journal of Physical Anthropology, 135, 56-63.

Noë, R., \& Bshary, R. (1997). The formation of red colobus-diana monkey associations under predation pressure from chimpanzees. Proceedings of the Royal Society of London Series B-Biological Sciences, 264, 253-259.

Oversluijs Vasquez, M. R., \& Heymann, E. W. (2001). Crested eagle (Morphnus guianensis) predation on infant tamarins (Saguinus mystax and Saguinus fuscicollis, Callitrichinae). Folia Primatologica, 72, 301-303. 
Peres, C. A. (1993). Anti-predation benefits in a mixed-species group of Amazonian tamarins. Folia Primatologica, 61, 61-76.

Popp, J. (1988). Scanning behavior of finches in mixed-species groups. Condor, 510-512.

Pöysä, H. (1994). Group foraging, distance to cover and vigilance in the teal, Anas crecca. Animal Behaviour, 48, 921-928.

Price, E. C., McGivern, A. M., \& Ashmore, L. (1991). Vigilance in a group of free-ranging cotton-top tamarins Saguinus oedipus. Dodo, Journal of the Jersy Wildlife Preservation Trust, 27, 41-49.

Pulliam, H. R. (1973). On advantages of flocking. Journal of Theoretical Biology, 38, 419-422.

Rettig, N. L. (1978). Breeding behavior of the harpy eagle (Harpia harpyja). Auk, 95, 629-643.

Robinson, S. K. (1994). Habitat selection and foraging ecology of raptors in Amazonian Peru. Biotropica, 26, 443-458.

Roda, S. A., \& Pontes, A. R. M. (1998). Polygyny and infanticide in common marmosets in a fragment of the Atlantic forest of Brazil. Folia Primatologica, 69, 372-376.

Rose, L., \& Fedigan, L. (1995). Vigilance in white-faced capuchins, Cebus capucinus, in Costa Rica. Animal Behaviour, 49, 63-70.

Savage, A., Snowdon, C. T., Giraldo, L. H., \& Soto, L. H. (1996). Parental care patterns and vigilance in wild cotton-top tamarins (Saguinus oedipus). In M. A. Norconk, A. L. Rosenberger, \& P. A. Garber (Eds.), Adaptive Radiations of Neotropical Primates (pp. 187-199). New York: Plenum Press.

Shahuano Tello, N., Huck, M., \& Heymann, E. W. (2002). Boa constrictor attack and successful group defence in moustached tamarins, Saguinus mystax. Folia Primatologica, 73, 146-148.

Smith, A. C., Kelez, S., \& Buchanan-Smith, H. M. (2004). Factors affecting vigilance within wild mixedspecies troops of saddleback (Saguinus fuscicollis) and moustached tamarins (S. mystax). Behavioral Ecology and Sociobiology, 56, 18-25.

Steenbeek, R., Piek, R., van Buul, M., \& van Hooff, J. A. R. A. M. (1999). Vigilance in wild Thomas's langurs (Presbytis thomasi): The importance of infanticide risk. Behavioral Ecology and Sociobiology, 45, 137-150.

Struhsaker, T. T. (1981). Polyspecific associations among tropical rainforest primates. Zeitschrift Für Tierpsychologie, 57, 268-304.

Sullivan, K. A. (1984). The advantages of social foraging in downy woodpeckers. Animal Behaviour, 32, $16-22$.

Terborgh, J. (1983). Five New World primates: A study in comparative ecology. Princeton, NJ: Princeton University Press.

Terborgh, J. (1990). Mixed flocks and polyspecific associations: Costs and benefits of mixed groups to birds and monkeys. American Journal of Primatology, 21, 87-100.

Tirado Herrera, E. R., Knogge, C., \& Heymann, E. W. (2000). Infanticide in a group of wild saddle-back tamarins, Saguinus fuscicollis. American Journal of Primatology, 50, 153-157.

Treves, A. (1998). The influence of group size and neighbors on vigilance in two species of arboreal monkeys. Behaviour, 135, 453-481.

Treves, A. (1999). Has predation shaped the social systems of arboreal primates? International Journal of Primatology, 20, 35-67.

Treves, A. (2000). Theory and method in studies of vigilance and aggregation. Animal Behaviour, 60, $711-722$.

Treves, A. (2002). Predicting predation risk for foraging, arboreal monkeys. In L. E. Miller (Ed.), Eat or be eaten: Predator sensitive foraging among primates (pp. 222-241). New York: Cambridge University Press.

van Schaik, C. P., \& van Noordwijk, M. A. (1989). The special role of male Cebus monkeys in predation avoidance and its effect on group composition. Behavioral Ecology and Sociobiology, 24, 265-276.

Yáber, M. C., \& Herrera, E. A. (1994). Vigilance, group-size and social status in capybaras. Animal Behaviour, 48, 1301-1307.

Zar, J. (1999). Biostatistical analysis. Upple Saddle River, NJ: Prentice-Hall. 